\title{
Quantificação da Geodiversidade do Geopark UNESCO Araripe
}

\author{
Quantification of Geodiversity of Geopark UNESCO Araripe \\ CARVALHO NETA ${ }^{1}$, M. L.; CORRÊA ${ }^{2}$, A. C. B.; BÉTARD ${ }^{3}$, F. \\ carvalhoneta@gmail.com
}

\begin{abstract}
Resumo
Apresenta-se um mapeamento quantitativo da Geodiversidade do Geopark UNESCO Araripe (GA) a partir da metodologia proposta por Bétard (2017). O método de aquisição de dados foi apresentado em detalhes por Carvalho et al (2018), que primeiro conduziu a um mapeamento qualitativo da geodiversidade do geopark. A cartografia foi gerada a partir de bancos de dados preexistentes, com escalas variando ente 1:200.000 e 1:600.000. A diversidade geológica e paleontológica do GA já é reconhecida e, as representações aqui expostas mostram que as diversidades geomorfológica, hidrológica e pedológica também são consideráveis. A quantificação apresentada aqui pode apoiar diferentes atividades na região, seja na reavaliação de geossítios e sítios de geodiversidade, na orientação das visitas de geocientistas e/ou não geocientistas, bem como na redefinição das ações de geoconservação.
\end{abstract}

Palavras-chave: Mapeamento quantitativo; Índice de Geodiversidade; Geopark UNESCO Araripe.

\begin{abstract}
A quantitative mapping of Geodiversity of UNESCO Araripe Geopark (GA) is presented using the methodology proposed by Bétard (2017). The data aquisition method was presented in detail by Carvalho-Neta et al (2018), that first conducted to a qualitative mapping of geopark geodiversity. The cartography was generated from preexisting databases, with scales varying between 1:200.000 and 1:600.000. The geological and palaeontological diversity of the GA is already recognized, and the representations presented here show that the geomorphological, hydrological and pedological diversities are also considerable. The quantification presented here can support different activities in the region, either in the reassessment of geosites and geodiversity sites, in the orientation of geoscientists and/or non geoscientists visits, as well as in redefining the actions of geoconservation.
\end{abstract}

Keywords: Quantitative mapping; Geodiversity Index; UNESCO Araripe Geopark.

\section{INTRODUÇÃO}

Apresenta-se uma quantificação da Geodiversidade do Geopark Araripe (GA) como desdobramentos do mapeamento apresentado por Carvalho-Neta et al (2018), o qual mostrou uma cartografia qualitativa da geodiversidade do recorte. O GA, localizado no sul do Estado do Ceará, compreende o território dos municípios de Crato, Juazeiro do Norte, Barbalha, Nova Olinda, Santana do Cariri e Missão Velha e, atualmente, conta com 9 geossítios prioritários para a geoconservação (Figura 1).

\footnotetext{
${ }^{I}$ Maria de Lourdes Carvalho Neta, Departamento de Geociências, Universidade Regional do Cariri, Crato-CE, Brasil.

${ }^{2}$ Antônio Carlos de Barros Corrêa, Universidade Federal de Pernambuco, Recife-PE, Brasil.

${ }^{3}$ François Bétard, Université Paris Denis Diderot, Paris, França.
} 

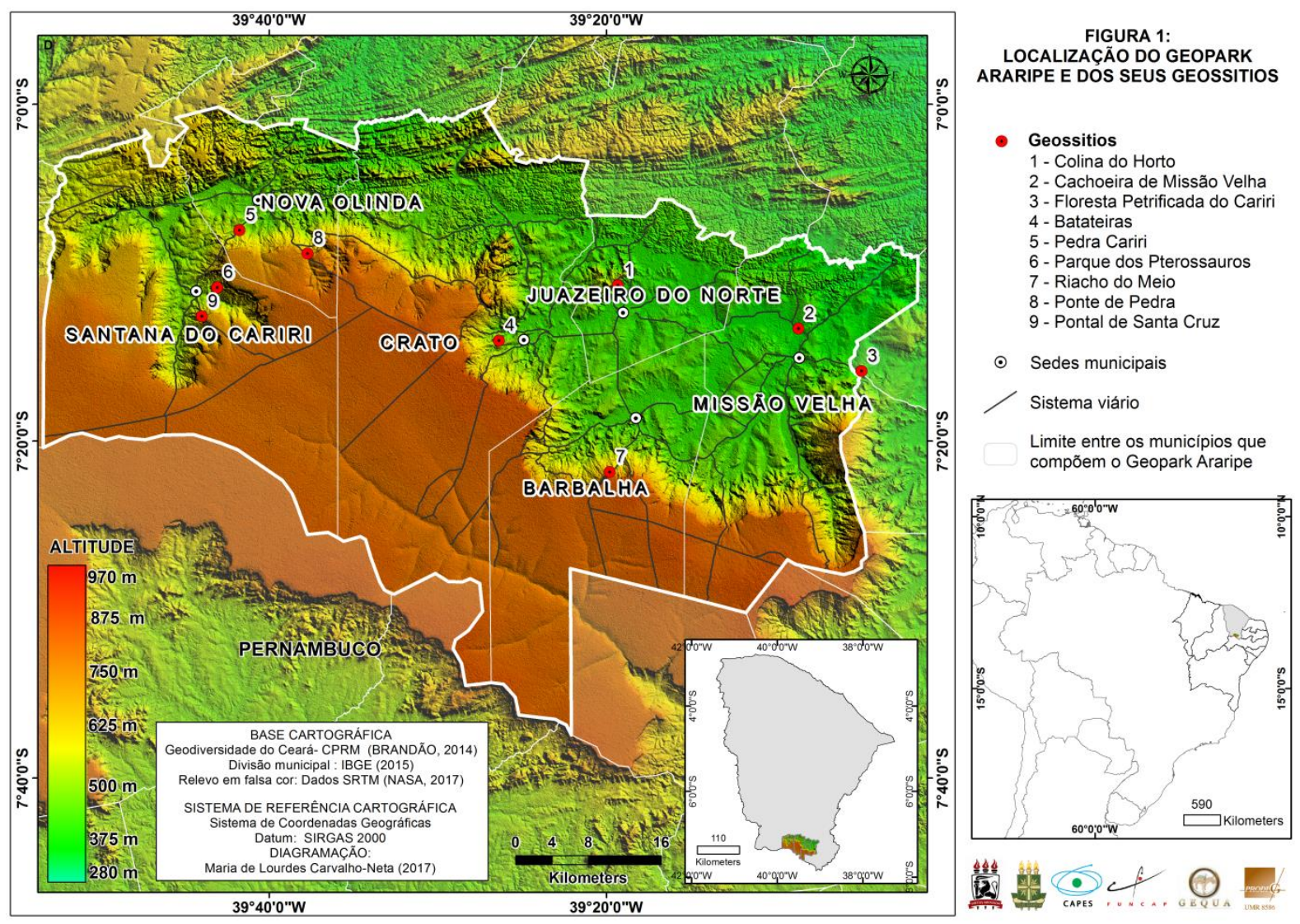

Figura 1 - Localização do Geopark Araripe e de seus geossítios. Fonte: Carvalho-Neta et al (2018).

Esses geossítios apresentam uma diversidade de valores associados. Alguns destes apresentam relevante interesse científico, como o Parque dos Pterossauros, a Floresta Petrificada do Cariri e a Pedra Cariri. Outros se destacam também por apresentar, além do interesse geológico, interesse histórico-cultural, como os geossítios Colina do Horto, Ponte de Pedra, Cachoeira de Missão Velha e Pontal de Santa Cruz; e outros pelo elevado interesse ecológico, como Riacho do Meio e o Batateiras (CEARÁ, 2012). Essa heterogeneidade também é uma característica marcante na geodiversidade do GA.

A definição de geodiversidade que orienta esta análise é proposta por Gray (2013). Esta é entendida como o conjunto da diversidade geológica (rochas, minerais, fósseis), geomorfológica (relevo), pedológica (solo) e hidrológica (águas superficiais e subterrâneas), e todos os processos que os geram. O mapeamento dos componentes da geodiversidade do GA apresentado por Carvalho-Neta et al (2018) demonstrou que a alta diversidade do Geopark não é apenas geológica e paleontológica. Ela é também geomorfológica, pedológica e hidrológica. 
A análise da geodiversidade pode ser de forma qualitativa e/ou quantitativa. Estudos de caráter qualitativo se concentram na descrição e análise dos valores da geodiversidade. São exemplos deste tipo de abordagem os trabalhos de Brilha (2005), Herzog et al (2008), Bento e Rodrigues (2011), Borba (2011), Lima (2011), Ceará (2012), Ruchkys et al (2015), Bétard et al (2017a) e Carvalho-Neta et al (2018). As análises de caráter quantitativas, no intuito de mensurar a riqueza e abundância da geodiversidade, têm se devolvido graças à utilização de ferramentas de geoprocessamento. Dentre as referências que apresentam análises este tipo de abordagem, analisamos as propostas apresentadas por Bétard (2017), Araújo e Pereira (2017), Pereira e Ruchkys (2016) e Pereira et al (2013). No entanto, é importante frisar que existem diversas outras metodologias que propõem uma avaliação quantitativa da geodiversidade (por exemplo: KOZLOWSKI, 2004; SERRANO, RUIZ-FLAÑO, 2007; BENITO-CALVO et al, 2009; RUBAN, 2010) e, estas metodologias podem adotar critérios diferenciados.

O objetivo do cálculo índice de geodiversidade é expressar, da maneira mais equilibrada possível, todos esses aspectos sem enfatizar qualquer elemento particular de geodiversidade (PEREIRA et al, 2013). Bétard (2017) e Araújo e Pereira (2017), ao concretizarem o cálculo de índice de geodiversidade para o estado do Ceará apresentaram o sul do estado do Ceará (onde está inserido o Geopark UNESCO Araripe) como uma área de alta geodiversidade. Dessa forma, viu-se à necessidade de se proceder ao cálculo do índice de geodiversidade, em uma escala mais detalhada, especificamente para o recorte do GA.

\section{MATERIAL E MÉTODO}

A quantificação da geodiversidade do GA considerou uma fase de levantamentos bibliográficos, especificamente na revisão das metodologias de mapeamento quantitativo da geodiversidade, seguida do cálculo dos índices e subíndices e, análise dos resultados. Como mencionado, a quantificação GA adotou a metodologia proposta por Bétard (2017) e foi gerado a partir do mapeamento qualitativo mostrada por Carvalho-Neta et al (2018).

O cálculo do índice de geodiversidade é obtido automaticamente, mediante as ferramentas de análise em ambiente de Sistema de Informação Geográfico-SIG, a partir da intersecção de mapas temáticos dos diferentes elementos da geodiversidade (a saber: geologia, geomorfologia, pedologia e hidrografia), com um plano de informações contendo uma malha quadricular (ou grid) com dimensões predefinidas. Pereira et al (2013) indicam que esta sobreposição de uma grade à um mapa é considerada uma ferramenta básica para a 
avaliação da geodiversidade de qualquer território. A grade fornece quadrados em que unidades e ocorrências podem ser contadas e a discriminação dos resultados alcançados.

Bétard (2017) apresentou proposta de cálculo do índice de geodiversidade para o Ceará. O tamanho da grade utilizada pelo autor foi de $10 \mathrm{kmx} 10 \mathrm{~km}$ e os mapas fonte, apresentam escalas variando de 1:500.000 a 1:5.000.000. Esta metodologia considera o equilíbrio dos diferentes componentes da geodiversidade. Baseado nos mesmos princípios (noção de riqueza ou "variedade") e ferramentas de estatísticas espaciais que as desenvolvidas por Pereira et al (2013), o método envolve o cálculo de quatro índices parciais correspondentes aos principais componentes da geodiversidade. (BÉTARD, 2017).

A figura 2 ilustra os dados utilizados no cálculo do índice de geodiversidade, resultante da soma dos quatro índices parciais: (1) diversidade geológica, que por sua vez é medido a partir da soma de três subíndices de diversidades (1.1) petrográfica ou litológica, (1.2) paleontológica e (1.3) mineralógica; (2) diversidade geomorfológica, mensurado pela adição de 2 subíndices (2.1) topografia e (2.2) morfologia; (3) diversidade hidrológica, resultante da soma de (3.1) diversidade hidrográfica, relacionada aos cursos hídricos superficiais e (3.2) hidrogeológica, relacionado ao potencial das águas subterrâneas; e (4) diversidade pedológica ou pedodiversidade, resultante da adição dos subíndices de (4.1) diversidade de solos e (4.2) ocorrência de paleossolos.

A integração dos dados se deu no software ArcGIS, o que possibilitou a manipulação de arquivos vetoriais e matriciais, e a criação de um banco de dados georreferenciados, onde todos os planos de informações foram convertidos para a projeção cartográfica Universal Transversa de Mercator - UTM, utilizando-se o Datum Sistema de Referência Geocêntrico para as Américas de 2000 - SIRGAS-2000.

Levando em consideração a dimensão do território do GA, a escala das bases cartográficas utilizadas (variáveis entre 1:200.000 e 1:600.000) e os testes a partir da superposição de grid de diferentes dimensões ( $5 \mathrm{~km}$ x $5 \mathrm{~km} ; 2,5 \mathrm{~km}$ x 2,5 km e $1 \mathrm{~km}$ x $1 \mathrm{~km}$ ), apresentam-se aqui os resultados alcançados a partir da superposição da malha de 2,5 km x $2,5 \mathrm{~km}$, resultando em 678 quadrados/pixels, com a finalidade de proporcionar a diferenciação mais precisa dos resultados. A figura 3 ilustra as etapas e bases da quantificação. 


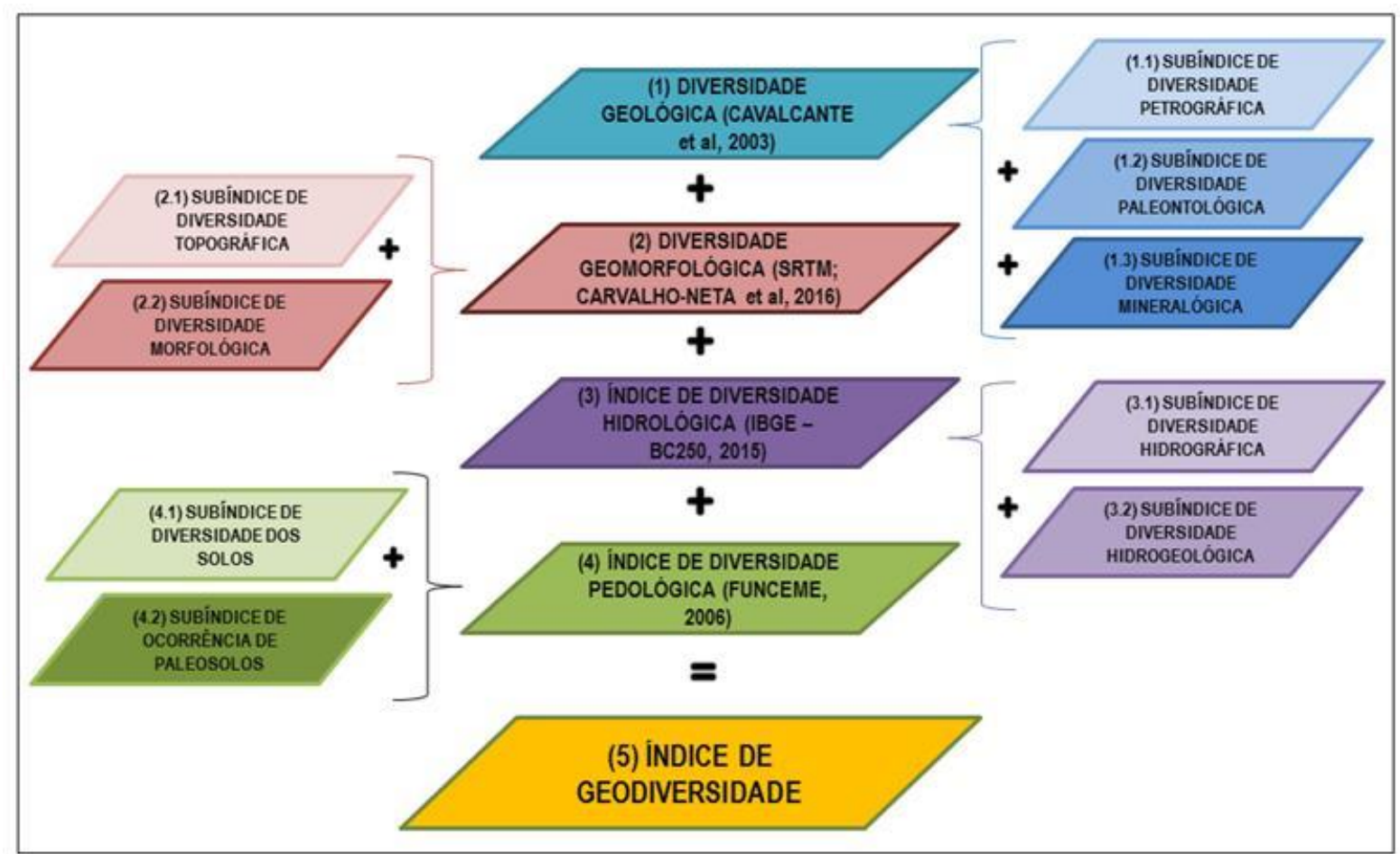

Figura 2 - Etapas e dados para o cálculo do índice de geodiversidade do GA. Fonte: Elaboração dos Autores (2018) a partir de Bétard (2017).

$\mathrm{Na}$ figura 3 (A) exemplificam-se o cálculo do índice de diversidade petrográfica/litológica. Soma-se, em cada pixel, o número diferente de unidades geológicas/litologias identificadas (na imagem, cada cor representa uma litologia). Se apenas 1 tipo de litologia é identificada na célula, o valor atribuído é 1 e, assim por diante, quantas litologias diferentes sejam identificadas por pixel. Na figura 3 (B) o cálculo do subíndice de ocorrências minerais é ilustrado. No caso de ocorrência, é atribuído o valor 1. No caso de ausência, atribui-se o valor zero. Se for identificada a ocorrência de um mesmo mineral mais de uma vez no mesmo pixel, apenas uma ocorrência é computada. O cálculo ocorre de forma automática e, está vinculado diretamente a qualidade das informações disponíveis nas bases cartográficas. Na sequiência, os valores de cada índice e/ou subíndices de diversidade foi normalizado em até cinco classes (nos dados aqui apresentados utilizou-se o classificador "intervalos iguais" ou Equal interval). A escala de valores diversificou-se de: 0 (zero), apontando para valor nulo ou inexistência de elementos (quando aplicável), muito baixo (valor 1), baixo (valor 2), médio (valor 3), alto (valor 4) e muito alto (valor 5), por exemplo. 

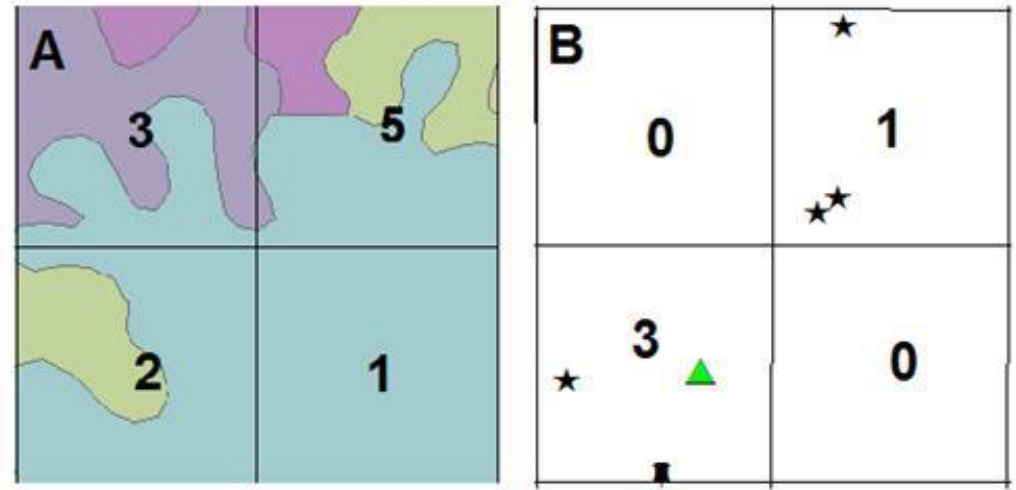

Figura 3 - Exemplos ilustrativos para o cálculo de índices de geodiversidade do GA. Fonte: Elaboração dos Autores (2018).

Procedeu-se a análise espacial em cada um dos temas, contando o número de ocorrências de atributos espaciais em cada uma das células ou pixels (como exemplificado acima) na geração dos quatro subíndices (ou índices parciais) de diversidade. Os subíndices são então somados, e os valores reclassificados (novamente em até cinco classes), para a geração do índice de geodiversidade do GA. Os resultados são expostos a seguir.

\section{RESULTADOS E DISCUSSÃO}

\subsection{A geodiversidade do Geopark Araripe}

A figura 4 expõe o mapeamento qualitativo dos componentes da geodiversidade (diversidade geológica, geomorfológica, hidrográfica e pedológica) do GA adaptados de Carvalho-Neta et al $(2016 ; 2018)$.

A diversidade geológica (figura 4 - A) considera o conjunto de características de petrologia, ocorrências/potencial mineralógico e paleontológico. Tratando da petrologia, o recorte possui litologias Pré-cambrianas (representadas por intrusões graníticas); rochas metamorfizadas, no contexto da Depressão Sertaneja, são representadas por associações de micaxistos, gnaisses, metacalcários e micaxistos, ortognaisses tonalito-granodioritos e ortognaisses e restos de paraderivadas. As litologias paleozóicas e mesozóicas, associadas à Bacia Sedimentar do Araripe, são notadas pelas Formações Mauriti, Brejo Santo, Missão Velha, Santana e Exu. Os sedimentos cenozóicos, representados pelas argilas, areias argilosas cascalhos, os sedimentos argilo-arenosos e depósitos de tálus, predominantemente, estão associados aos aluviões das planícies fluviais. (CARVALHO-NETA et al, 2018). Registra-se a atualização dos dados de litologia a partir de Cordeiro et al (2018), que definiram as áreas 
consideradas como "sedimentos elúvio-coluvial" como coberturas laterítica, identificadas na legenda do mapa (figura 4 - A). A ilustração ainda traz informações da potencialidade fossilífera das litologias, bem como da ocorrência de minerais.

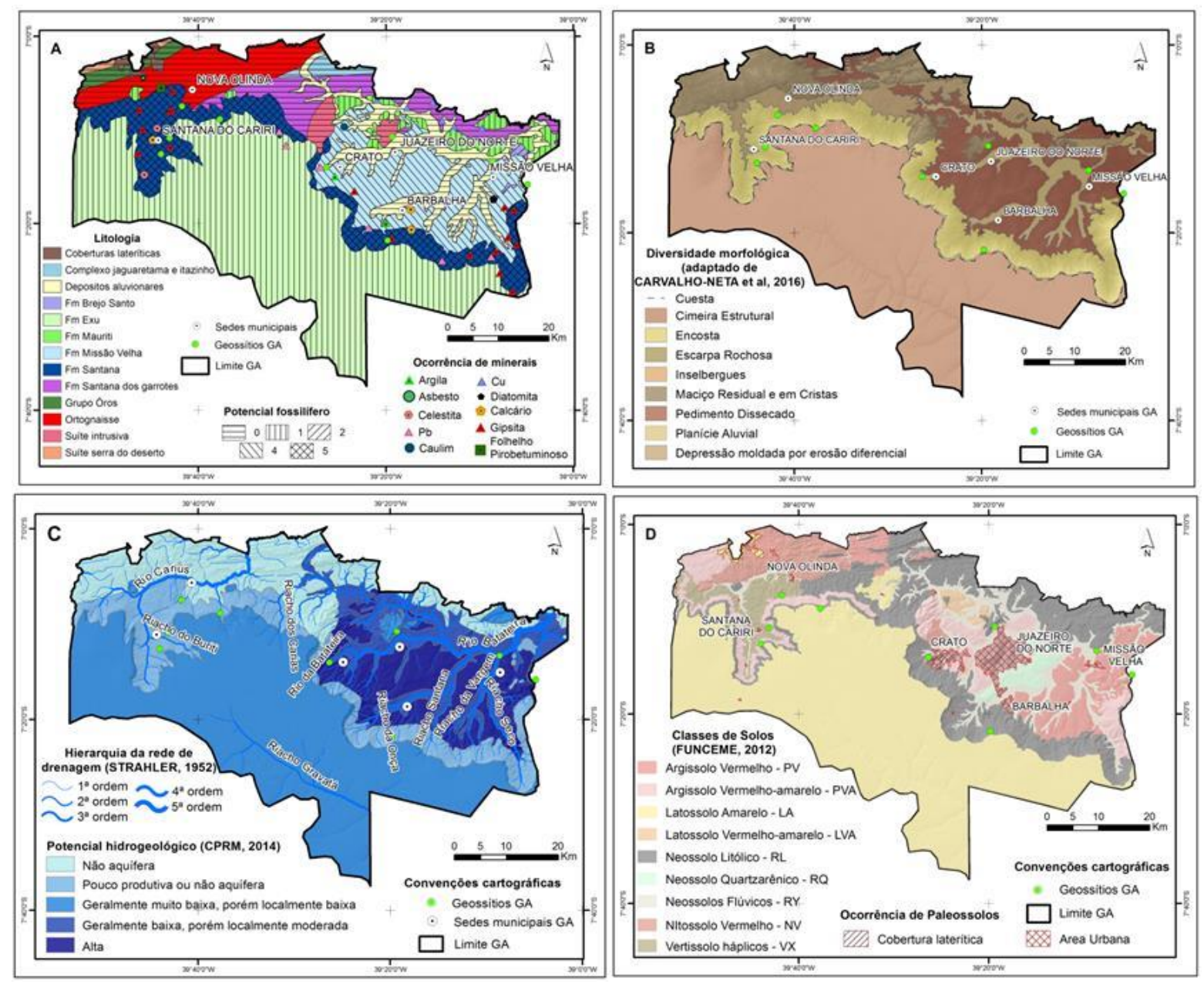

Figura 4 - Mapeamento qualitativo da geodiversidade do GA: A Diversidade Geológica;

B Geomorfológica; C Hidrográfica; D Pedológica. Fonte: Elaborado pelos autores, adaptado de Carvalho-Neta et al $(2016 ; 2018)$.

A representação da diversidade geomorfológica do GA é analisada pela associação da hipsometria (ver figura 1) e das unidades morfológicas (figura 4 -B). Identificam-se altitudes variando entre 280 e 970 metros. As altitudes mais elevadas estão relacionadas ao planalto sedimentar do Araripe que, ao total, cobre uma superfície de aproximadamente $180 \mathrm{~km}$ de comprimento (na direção leste-oeste) e largura variável entre 30 e $50 \mathrm{~km}$, compreendendo o extremo sul do Ceará, noroeste de Pernambuco e leste do Piauí (SOUZA, 2007). O desnível médio do topo até a sua base pode chegar a 300m. (CEARÁ, 2012). As áreas de altitudes menos elevadas estão associadas à depressão periférica e ao vale do Cariri. 
Tratando das unidades geomorfológicas, foram definidas oito unidades: Cimeira estrutural do Araripe; Escarpa rochosa, Encosta, Maciço residual e em cristas; Depressão moldada por erosão diferencial; Inselbergues; Pedimento dissecado e Planície aluvial. Segundo Carvalho-Neta et al (2016), estas feições geomorfológicas mapeadas denotam a influência geológica na gênese e os processos que comandam a dinâmica geomorfológica da área do Geopark Araripe, revelando que na escala da análise proposta as formas analisadas são marcadamente estruturais.

Sobre a diversidade hidrológica do GA (figura $4-\mathrm{C}$ ), observa-se que o recorte é bem drenado por diferentes rios e riachos, excetuando-se o topo do planalto do Araripe. Esses cursos fluviais foram hierarquizados a partir da proposta de Strahler (1952). Dentre os principais, destacam-se: Rio Salgado, das Cuncas, Batateiras, Cariús, Riacho dos Porcos e Salamanca. Tratando da hidrogeologia, o recorte apresenta um dos mais importantes sistemas aqüífero do Nordeste do Brasil - o aqüífero Missão Velha-, que dispõe das melhores unidades armazenadoras de águas subterrâneas do Estado do Ceará (VERÍSSIMO et al, 2008).

Sobre esta potencialidade hidrogeológica, Cordeiro et al (1984) apontam que a Formação Cariri ou Mauriti apresenta uma potencialidade hidrogeológica média, muito embora não possua um padrão rígido, devido a sua marcante descontinuidade. Sua alimentação é feita por infiltração direta da pluviometria e por aquíferos superiores. O aqüífero Missão Velha apresenta permeabilidade intersticial elevada, alimentação por infiltração pluvial direta. A Formação Santana é de baixa vocação hidrogeológica, apresentando poços de baixas vazões (águas de pequenas fraturas) e algumas vezes totalmente secos, tornando desaconselhável sua exploração. A Formação Exu expõe aqüífero potencialmente bom. A camada é alimentada por infiltração pluvial direta. (CORDEIRO et al, 1984).

Ao tratar da diversidade pedológica (figura 4 - D), que leva em consideração a variedade de classes de solos, bem como a ocorrência de paleossolos, identificaram-se Argissolos, Latossolos, Neossolo Litólicos, Neossolo Quatzarênicos, Neossolo Flúvicos, Nitossolos e Vertissolo (FUNCEME, 2012). O mapeamento de paleossolos foi orientado pelas informações apresentadas por Cordeiro et al (2018) e Peulvast e Bétard (2015), que identificaram áreas com presença de coberturas lateríticas.

\subsection{O Índice de geodiversidade do GA}


A quantificação da geodiversidade do GA foi realizada a partir do somatório dos índices e subíndices de cada elemento da geodiversidade (geologia, geomorfologia, pedologia e hidrografia). Trabalhou-se a partir dos dados cartográficos disponíveis. Sendo de elaboração dos autores, a definição das unidades geomorfológicas. As figuras 5 e 6 ilustram os resultados do cálculo desses índices parciais de geodiversidade do GA e seus subíndices.

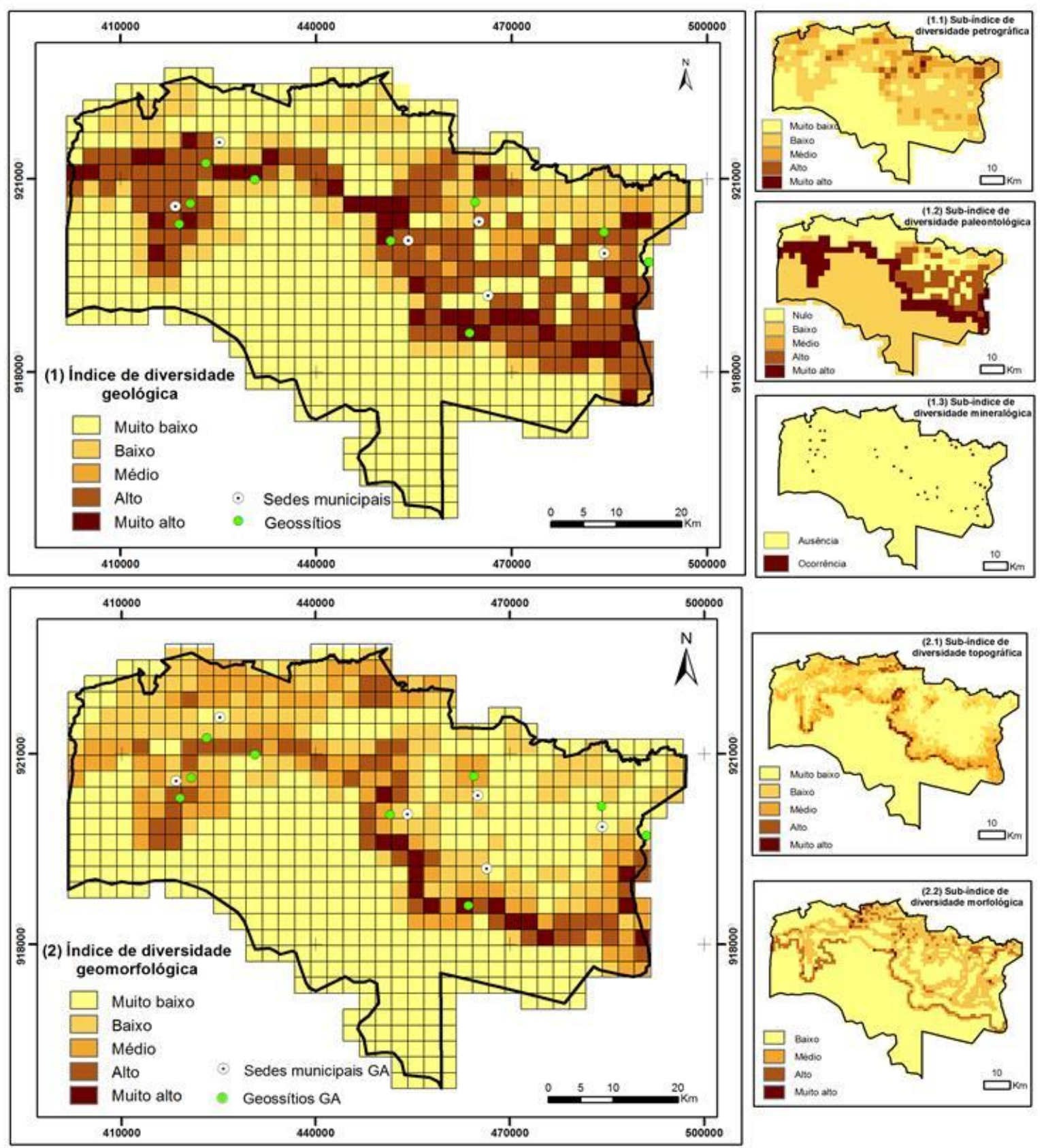

Figura 5 - Índices parciais e subíndices: (1) Diversidade Geológica e (2) Geomorfológica do GA. Fonte: Elaboração dos Autores (2018). 
O (1) índice de diversidade geológica (figura 5) considerou a diversidade litológica, a potencialidade paleontológica e as ocorrências mineralógicas. Considerando a litologia, os valores variaram de 1 a 4, de acordo com o número de litologias diferentes identificadas em um único pixel. No caso de ocorrência mineralógica, atribuiu-se o valor de 1 . No caso de ausência, valor zero. Ao tratar da paleontologia, somou-se de 0 (Zero) a 5 pontos, dependendo do potencial paleontológico que a literatura atribui à litologia. O rico acervo paleontológico, conhecido internacionalmente (BACCI, 2009), principalmente da Formação Santana, justificam a potencialidade nível 5 a ela atribuída. A Formação Missão Velha apresenta valor 4. A Formação Brejo Santo apresenta média potencialidade, justificando o valor 2. À Formação Exu e Mauriti atribuíram-se o valor 1. Às áreas cristalinas e metamórficas, consideradas afossilíferas atribui-se o valor 0 (zero). Estes valores foram atribuídos com base no plano de informações "ocorrências fossilíferas" do GeoSGB - Sistema de Geociências do Serviço Geológico do Brasil - CPRM. Ao tratar da aptidão para exploração de recursos minerais, a maior ocorrência é dos calcários laminados, os depósitos de gipsita e de argila e a água mineral.

Posterior ao cálculo de cada subíndice, os arquivos vetoriais foram convertidos em raster e, os subíndices foram somados, utilizando-se a função "Raster calculator", para se chegar ao valor do índice de diversidade geológica do GA (figura 5 - 1). Ao final, os valores foram reorganizados em 5 classes, variando de Muito baixo (valores 1 e 2), baixo (valor 3), médio (5 e 5), alto (6 e 7), muito alto (8 e 9). Como dito anteriormente, o recorte da bacia sedimentar do Araripe, o qual o GA está inserido, é conhecido mundialmente pela sua diversidade geológica e paleontológica. Os resultados apresentados na figura 5 ilustram bem essa riqueza de diversidade. Observa-se a diversidade mais alta nas áreas da exposição da Formação Santana, por conta do potencial fossilífero, bem como pelo fato de apresentar uma faixa estreita de exposição, caracterizando uma variação de litologias considerável para mesmo pixel.

O (2) índice de diversidade geomorfológica (figura 5) foi calculado a partir da soma dos subíndices de diversidade topográfica e o de diversidade morfológica. O subíndice de diversidade topográfica foi gerado a partir de Modelo Digital de Terreno - MDT. Para o cálculo do subíndice a partir deste raster, utilizou-se a ferramenta disponível no ArcGIS seguindo o seguinte caminho: ArcToolBox > Spatial Analyst > Zonal > Zonal Statistics. Indicou-se "Range" como tipo de estatística, a qual permite calcular, para cada quadrado (pixel) da grade, a diferença entre a altitude máxima e a altitude mínima no MDT. O 
subíndice de diversidade morfológica segue o mesmo procedimento de diversidade litológica (e também de pedologia), ou seja, o de riqueza/variedade de unidades de relevo ou tipos de litologias ou classes de solos por cada pixel (unidade da grade que mede $2,5 \mathrm{~km}$ x $2,5 \mathrm{~km}$ ). Observa-se uma baixa diversidade geomorfológica no topo do planalto sedimentar do Araripe. Os setores de contato entre cimeira estrutural, escarpa rochosa e encosta são os que apresentam maior diversidade.

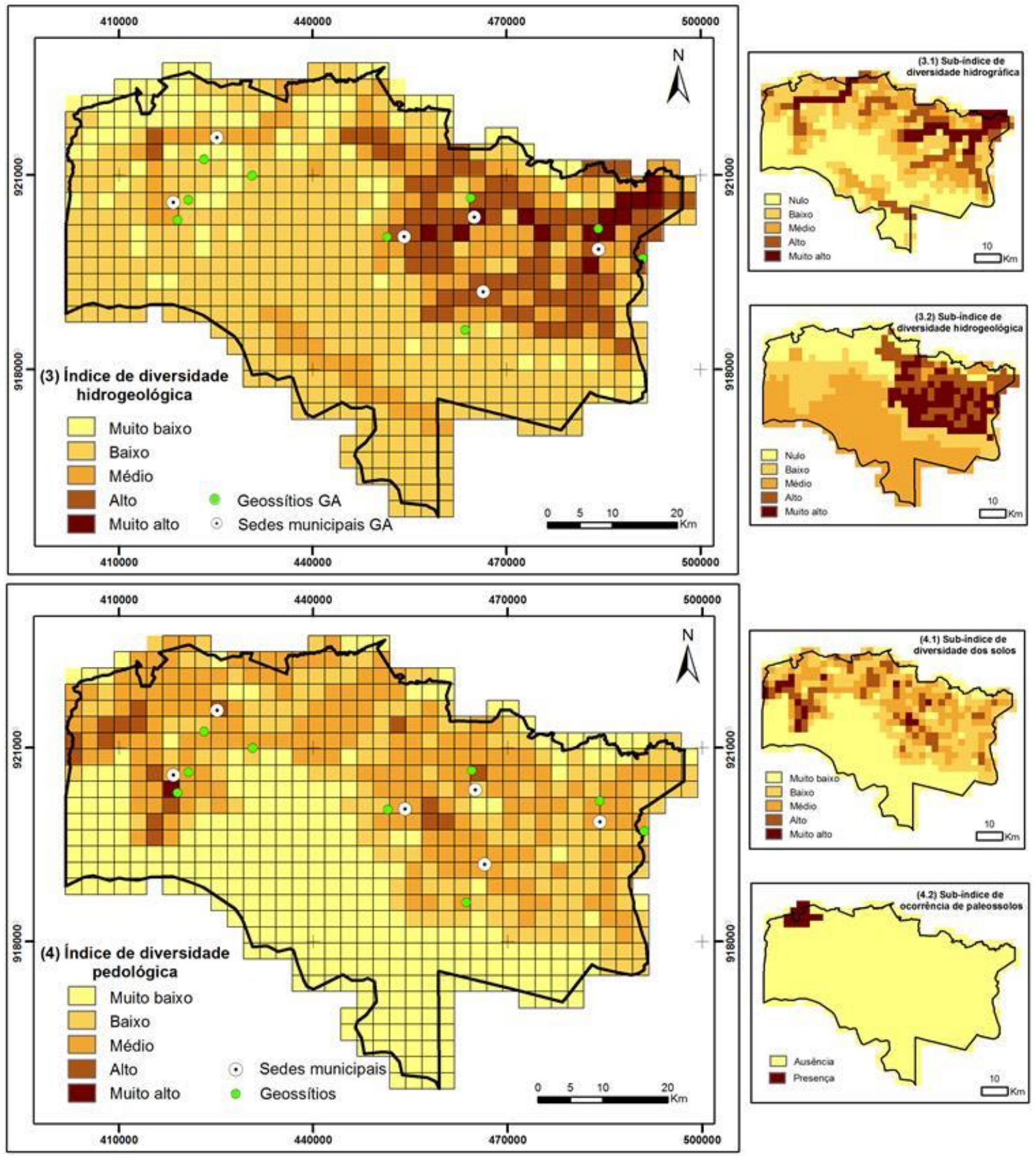

Figura 6 - Índices parciais e subíndices: (3) Diversidade Hidrogeológica e (4) Pedológica do GA. Fonte: Elaboração dos Autores (2018). 
Para o cálculo do (3) índice de geodiversidade hidrológica (figura 6), considerou-se a rede hidrográfica superficial e as potencialidades de águas subterrâneas. A hierarquização dos cursos fluviais foi essencial para o cálculo do subíndice da diversidade hidrográfica. Para o cálculo do subíndice de hidrogeologia, atribuiu-se valores variando de 0 (zero - nulo) a 4 (produtividade alta): o valor 0 (zero) foi designado às coberturas cristalinas, 1 para as coberturas sedimentares pouco produtivas ou não aqüíferas da Formação Santana e Brejo Santo; o valor 2, para as coberturas sedimentares da Formação Mauriti e Exu, tidas como produtivamente baixa, porém localmente baixa. À Formação Missão velha, de produtividade alta, foi atribuído o valor 4. Como pode ser observado na figura 5, o setor mais a leste do recorte de estudo apresenta mais ampla diversidade hidrológica. Tal diversidade é justificada pela presença de inúmeros rios e riachos, assim como a concentração dos de maior importância (maior hierarquia, na classificação com base na metodologia de STRAHLER, 1952), bem como pela presença do aqüífero Missão Velha.

O (4) índice de diversidade pedológica (figura 6) foi mensurado a partir do subíndice de diversidade dos solos e do mapeamento da ocorrência de paleossolos. Observa-se a baixa diversidade de solo, - que seguiu o critério de riqueza ou variedade de classe de solos para cada pixel-, no topo do planalto do Araripe, onde predominam os Latossolos amarelos (vasta área sem variação). No setor oeste do recorte, proximidades da sede do município de Santana do Cariri, numa área de confluência entre Vertissolos, Argissolos e Neossolos a diversidade apresenta-se mais elevada. Além disso, identifica-se a ocorrência de laterita na porção superior do setor oeste do GA.

A figura 7 ilustra o índice de geodiversidade do GA. Esta cartografia é resultante da soma dos 4 índices parciais apresentados anteriormente. Os valores foram reorganizados em até cinco classes.

Observa-se que o território do Geopark UNESCO Araripe apresenta pontos de geodiversidade bastante elevados. Os valores foram reorganizados pelo método classificador "intervalos iguais" (Equal interval). Percebe-se que, em algumas destes setores de geodiversidade elevada, estão definidos os geossítios abertos à visitação, como é o caso do Geossítio Riacho do Meio. No entanto, alguns pontos/setores mapeados como de elevada geodiversidade, não apresenta geossítios ou sítios de geodiversidade definidos. 


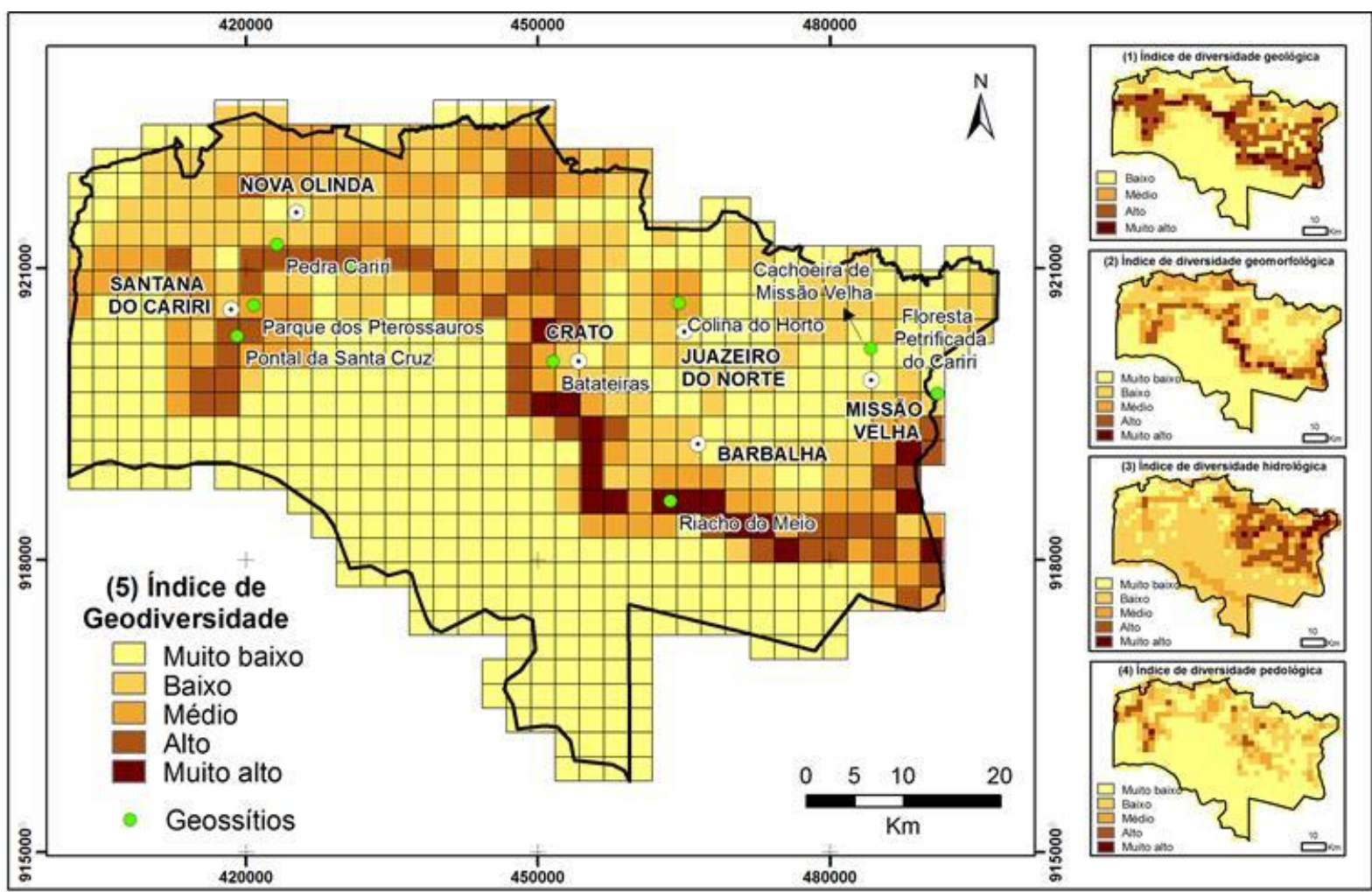

Figura 7 - Índice de geodiversidade do GA e seus índices parciais. Fonte: Elaboração dos Autores (2018).

Outra ponderação que a quantificação da geodiversidade permite, é a proximidade dos geossítios à sede urbana dos municípios. Por um lado, esta proximidade pode ser avaliada como um fator positivo, por uma questão de acessibilidade aos pontos. Por outro, considera-se a pressão que a proximidade de áreas urbanas pode causar a estes geossítios e à geodiversidade de maneira geral. Sobre isso, Bétard (2017), Bétard et al (2017b; 2017b) advertem que o GA além de ser uma área de grande geodiversidade e também de forte pressão das ameaças relacionadas às formas de uso e ocupação, o que indica a necessidade de medidas urgentes de conservação sobre estes dois critérios.

\section{CONSIDERAÇÕES FINAIS}

A quantificação da geodiversidade do Geopark Araripe comprova a alta diversidade apontada por Carvalho-Neta et al (2018), Bétard (2017), Bétard et al (2017a), entre outros. O método empregado mostrou-se satisfatório no cumprimento dos objetivos e alcance dos resultados. Como os resultados estão diretamente relacionados às bases, à medida que ocorra atualização dos dados cartográficos e/ou disponibilização de bases mais detalhamento 
(maiores escalas) e, também motivado pelos avanços em pesquisas científicas, este mapeamento pode e deve ser revisto.

Este mapeamento quantitativo faz parte de uma análise mais ampla, que trata da avaliação qualitativa e quantitativa da geodiversidade da Bacia Sedimentar do Araripe, bem como das ameaças à geodiversidade do território em questão. A partir desta quantificação, propõe-se ainda, uma reavaliação dos geossítios e/ou sítios de geodiversidade do território do Geopark, bem como da bacia sedimentar do Araripe (trabalhos em andamento).

\section{AGRADECIMENTOS}

À Fundação Cearense de Apoio ao Desenvolvimento Científico e TecnológicoFUNCAP, pelo apoio financeiro à pesquisa (Bolsa de Doutorado Fora do Estado); À Coordenação de Aperfeiçoamento de Pessoal de Nível Superior-CAPES pela concessão de bolsa de Doutorado Sanduíche no Exterior-PDSE (Processo n 88881.133740/2016-01); Ao Pôle de Recherche pour l'Organisation et la Diffusion de l'Information GéographiquePRODIG, pela acolhida durante o Doutorado Sanduiche (Set/2017 a Fev/2018).

\section{REFERÊNCIAS}

ARAÚJO, A. M.; PEREIRA, D. I. A New Methodological Contribution for the Geodiversity Assessment: Applicability to Ceará State (Brazil). Geoheritage. DOI 10.1007/s12371-0170250-3, 2017.

BENITO-CALVO, A.; PÉREZ-GONZÁLEZ, A.; MAGRI, O.; MEZA, P. Assessing regional geodiversity: The Iberian Peninsula. Earth Surface Processes and Landforms, 34(10), 2009. 1433-1445p.

BENTO, L. C. M.; RODRIGUES, S. C. Geodiversidade e potencial geoturístico do Salto de Furnas - Indianópolis-MG. RA'EGA. Curitiba, Departamento de Geografia - UFPR: 21, 2011. 272-297p.

BÉTARD, F. Géodiversité, biodiversité et patrimoines environnementaux. De la connaissance à la conservation et à la valorisation. Mémoire d'Habilitation à Diriger des Recherches, Université Paris-Diderot: Paris, 2017. 2 volumes, 270 p. e 316p.

PEUlVAST J-P; MAGAlHÃES, A.O; CARVAlHO-NETA, M. L.; FREITAS, F.I. Araripe Basin: A Major Geodiversity Hotspot in Brazil. Geoheritage, 2017a. doi:10.1007/s12371-017-0232-5. 
PEUlVAST, J-P., MAGAlHÃES, A. O., FREITAS, F. I. Géopatrimoine et biopatrimoine, à la croisée entre conservation et développement. Une approche des trajectoires patrimoniales dans le Cariri du Ceará (Nordeste brésilien). Annales de Géographie, 717, 2017b, 544-565.

BORBA, A. W. de. Geodiversidade e Geopatrimônio como bases para estratégias de geoconservação: conceitos, abordagens, métodos de avaliação e aplicabilidade no contexto do Estado do Rio Grande do Sul. Pesquisas em Geociências, Porto Alegre: 38 (1), jan./abr. 2011. 03-14p.

BRANDÃO, R. de L. FREITAS, L. C. B. (Org.) Geodiversidade do estado do Ceará. Fortaleza: CPRM, 2014. 214 p. Disponível em: www.cprm.gov.br

BRILHA, J. Patrimônio Geológico e Geoconservação: a conservação da natureza na sua vertente geológica. Palimage: Braga, 2005.

CARVALHO NETA, M. de L.; CORREA, A. C. B.; SILVA, D. G.. Esboço Geomorfológico do Geopark Araripe/CE como ferramenta para a Geoconservação. In: XI Simpósio Nacional de Geomorfologia-SINAGEO, 2016, Maringá. Anais do XI Simpósio Nacional de Geomorfologia - SINAGEO, 2016. v. único.

BÉTARD, F. CORREA, A. C.B. Mapeamento da geodiversidade do Geopark Araripe. In: XII Simpósio Nacional de Geomorfologia-SINAGEO, 2018, Crato. Anais do XII Simpósio Nacional de Geomorfologia - SINAGEO, 2018. v. único.

CAVAlCANTE, J. C.; VASCONCELOS, A. M.; MEDEIROS, M. de F.; PAIVA, I. G. Mapa geológico do estado do Ceará. Fortaleza: CPRM, 2003.

CEARÁ. Geopark Araripe: Histórias da Terra, do Meio Ambiente e da Cultura. Programa Cidades do Ceará - Cariri Central, Secretaria das Cidades. Fortaleza: 2012.

CORDEIRO, W.; GONÇALVES, J. Y. B.; HOLANDA, C. H. N. Sinopse da Hidrogeologia do Estado do Ceará. Revista Águas Subterrâneas - Anais do III Congresso Brasileiro de Águas Subterrâneas, 1984.

CORDEIRO, A. M. N.; BASTOS, F. H.; MAIA, R. P. Formações concrecionárias e aspectos genéticos e evolutivos do Maciço do Quincuncá, Província Borborema, Nordeste do Brasil. Revista Brasileira de Geomorfologia (Online). São Paulo, v.19, n.2, (Abr-Jun) p.359-372, 2018.

CPRM. Projeto de disponibilidade hídrica do Brasil - Carta Hidrogeológica - Folha SB.24 Jaguaribe. Rio de Janeiro: CPRM, 2015.

FUNCEME, Fundação Cearense de Meteorologia e Recursos Hídricos. Levantamento de reconhecimento de média intensidade dos solos da Mesorregião do Sul Cearense. MAPAS. Fortaleza, 2012. 98p.

Levantamento de reconhecimento de média intensidade dos solos da Mesorregião do Sul Cearense. Fortaleza, 2012. 280p. 
GEOSGB. Sistema de Geociências do Serviço Geológico do Brasil - CPRM. Disponível em: http://geosgb.cprm.gov.br. Acesso em 16 de janeiro de 2018.

GRAY, M. Geodiversity: valuing and conserving abiotic nature. John Wiley \& Sons, $2^{\text {a }}$ Ed. 2013.

HERZOG, A. L.; SALES, A., HILlMER, G. The UNESCO Araripe Geopark: A Short Story of the Evolution of Life, Rocks and Continents. Expressão Gráfica e Editora, Fortaleza, 2008.

HERZOG, A. L. Paisagens Geológicas e Geoparques: o Geoparque Araripe. In: MONGELLI, M. de M.; CASTRIOTA, L. B. (Editores). $1^{\circ}$ Colóquio Ibero-americano Paisagem Cultural, Patrimônio e Projeto, Edition: 1a, Chapter: IV Parte, Publisher: IPHAN, 2017. pp.420-435.

IBGE. Base Cartográfica Contínua do Brasil 1:250 000 - BC250. $2^{\mathrm{a}}$ Ed. - versão digital com banco de dados geográfico. Instituto Brasileiro de Geografia e estatística - IBGE: Rio de Janeiro, 2015.

KOZLOWSKI, S. Geodiversity. The concept and scope of geodiversity. Przeglad Geologiczny, 52(8/2), 2004. 833-837p.

LIMA, F. F. de. Diagnóstico do Patrimônio Geológico do Geopark Araripe no âmbito do Projeto de Desenvolvimento Econômico Regional do Ceará. Governo do Estado do Ceará: Crato, 2011.

PEREIRA, E. O. RUCHKYS, U. Quantificação e análise da geodiversidade aplicada ao geoturismo na área de proteção ambiental Sul da Região Metropolitana de Belo Horizonte, Minas Gerais. RA'EGA. Curitiba, v.37, Ago/2016. 207-226p.

PEREIRA, D. I.; PEREIRA, P.; BRILHA, J.; SANTOS, L. Geodiversity assessment of Paraná State (Brazil): An innovative approach. Environmental Management, 52(3), 2013. pp. 541-552.

PEULVAST, J-P., BÉTARD, F. A history of basin inversion, scarp retreat and shallow denudation: the Araripe basin as a keystone for understanding long-term landscape evolution in NE Brazil. Geomorphology, 233, 2015. pp. 20-40.

RUBAN, D.A.Quantification of geodiversity and its loss. Proceedings of the Geologists' Association, 121(3), 2010. 326-333p.

SERRANO, E.; RUIZ-FLAÑO, P. Geodiversity. A theoretical and applied concept. Geogr. Helv., 62(3), 2007. 140-147 p.

VERÍSSIMO, L. S.; AGUIAR, R. B. de. Hidrogeologia da Porção Oriental da Bacia Sedimentar do Araripe. Relatório Diagnóstico do Estado-da-Arte. Fortaleza: FINEP/CPRM/UFC, 2005. 
Recebido em: 12/08/2019

Aceito para publicação em: 25/09/2019 